\title{
Prevalence of Cardiovascular risk factors among the residents of urban community of Kathmandu municipality.
}

\author{
Amrit Bogati, Reeju Manandhar, Deewakar Sharma, Sajan G. Baidhya , Dipanker Prajapati , Sebina Baniya, \\ Neha Bista, Sagun Khanal, Sudha Ranabhat
}

Department of Cardiology, Shahid Gangalal National Heart Centre, Bansbari, Kathmandu, Nepal.

Corresponding Author: Amrit Bogati,

Department of Cardiology,

Shahid Gangalal National Heart Centre, Bansbari, Kathmandu, Nepal

Email address: bogati_amrit@hotmail.com

\section{Abstract}

\begin{abstract}
Background and Aims: The prevalence of risk factors for cardiovascular diseases is globally increasing leading to the increase in mortality and morbidity due to cardiovascular diseases. The objective of this study is to assess the prevalence of cardiovascular risk factors among the residents of urban community of Kathmandu municipality.

Methods: By using simple random sampling method, we selected 130 participants aged 18 years or above, from the voters list of ward no.22 of Kathmandu. Male participants aged less than 45 and female participants aged less than 55 were grouped as young age group which included total of $80(61.5 \%)$ participants and rest were grouped as old age group. All the participants gave the informed consent. Statistical analysis was done using SPSS software version 20.

Results: The mean age of the participants was 46.6 years with $53.8 \%$ male. Insufficient physical activity $(68.5 \%)$, high waist circumference $(67.7 \%)$ were the two most prevalent risk factors followed by obesity $(59.2 \%)$, hypertension $(37.7 \%)$, tobacco consumption $(37.5 \%)$, dyslipidemia $(22.3 \%)$ and diabetes $(16.9 \%)$ in overall population. Tobacco consumption were more prevalent in male participants of both younger and older age groups whereas high waist circumference was prevalent in female participants of both age group.

Conclusion: Our study showed high prevalence of insufficient physical activity, high waist circumference, obesity, hypertension and tobacco use among urban population of Kathmandu, suggesting possibility of higher incidence of cardiovascular disease in future, pointing towards the need of aggressive preventive strategy to prevent epidemic of cardiovascular disease.
\end{abstract}

Keywords : Cardiovascular; Prevalence; Risk Factors; Urban population.

\section{Introduction}

Heart disease accounts for the single most frequent cause of morbidity and mortality. ${ }^{1}$ In recent times, there is increasing trend in cardiovascular diseases (CVD) mortalities in developing and under-developed countries, which is due to early manifestation of various risk factors like diabetes, dyslipidemia, hypertension, leading to increase in incidence of atherosclerotic diseases. ${ }^{2}$ About one third of all deaths in Nepal are caused by four major non communicable disease, among them cardiovascular disease is a front runner. ${ }^{3}$ Abnormal lipids, smoking, hypertension, diabetes, and so on, are the risk factors for myocardial infarction worldwide in both sexes and at all ages. ${ }^{3,4}$ This study was conducted to assess the prevalence of such cardiovascular risk factors among the residents of urban community of Kathmandu municipality, so that, approaches for prevention can be initiated to prevent most premature cases of cardiovascular disease.

\section{Methods}

\section{Study settings}

The study was conducted in ward no. 22 of Kathmandu Metropolitan city, a small town with urban population. Random sampling method was used to select the study population from the voters list of that particular area. Sample size was calculated by using online sample size calculator provided by Raosoft, with population size of 1777 , margin of error was set to $5 \%$, confidence level was $95 \%$, and the calculated sample size was 129 . So, 130 patients were randomly selected from the voter list of 1777 using random number generator.

The selected members aged 18years and above, underwent questionnaire survey in Nepali language. The participants were invited to a predefined medical centre in the local community for blood sampling, anthropometrical measurements and other needful. Written consent was taken from all the respondents for their participation in this study. All the necessary evaluation and monitoring was conducted by a professional team which was spearheaded by a medical doctor.

\section{Questionnaire}

The survey questionnaire covered the demographics and health behavior of participants. Demographic information included date of birth (age), sex, ethnicity, marital status, years at school and primary occupation. The health behavior covered in the 
questionnaire included tobacco use, alcohol consumption, fruit and vegetable consumption, physical activity, history of raised blood pressure and raised blood glucose, oral health, and dietary salt consumption.

Doctor's Aneroid Sphygmomanometer (BP Set) was used for recording blood pressure. We recorded two readings of systolic and diastolic blood pressure; one at the beginning of the interview and the other at the end. The two measurements were averaged for final score. Blood pressure $\geq 140 / 90 \mathrm{mmHg}$ or taking antihypertensive medication was considered as hypertension which was based on the Seventh Report of the Joint National Committee on prevention, detection, evaluation and treatment of high blood pressure (JNC 7) criteria. ${ }^{5}$

Alcohol and tobacco consumption were considered present if the participants had habit of taking them until the past 30 days of interview. Adequate physical exercise was defined as moderate exercise of 30 minutes at least 5 days a week (150 minutes a week).

Height and weight were measured and body mass index (BMI) was calculated. Waist and hip circumference were also measured in order to determine the waist-hip ratio. Height was recorded in centimeters, with a portable standard stature scale. Weight was recorded in kilograms using portable digital weighing machine. Waist circumference was measured using a constant tension tape. Waist circumference(WC) was taken at the end of a normal expiration with the arms relaxed at the sides at the mid-point between the lower margin of the last palpable rib and the uppermost point of the iliac crest (hip bone).High $\mathrm{WC}$ and obesity was defined based on criteria modified for South Asians (WC $\geq 90 \mathrm{~cm}$ in men and $\geq 80 \mathrm{~cm}$ in women and $\mathrm{BMI} \geq 25$ $\mathrm{kg} / \mathrm{sq} \mathrm{m}$ respectively) $)^{5}$.

Electrocardiogram and blood investigations which included Fasting blood sugar level, lipid profiles and renal function test were measured. Diabetes Mellitus was diagnosed according to the World Health Organization diagnostic criteria. ${ }^{6}$ For the blood sugar measurement, whole blood was collected in evacuated tubes containing $\mathrm{NaF}$. Plasma Glucose was measured with a modified hexokinase enzymatic method. Diabetes was defined as having a fasting plasma glucose level $\geq 7.0 \mathrm{mmol} / \mathrm{L}$ and/or self reported current treatment with anti-diabetic medication (Insulin or oral hypoglycemic agents).

Lipid measurements were standardized according to the criteria of the Centers for Disease Control and PreventionNational Heart, Lung, and Blood Institute Lipid Standardization Program. ${ }^{7}$ For participants with a triglyceride level $<4.5 \mathrm{mmol} / \mathrm{L}$, LDL cholesterol levels were calculated from the Friedewald equation (LDL cholesterol= total cholesterol - HDL cholesterolTriglycerides/5). Dyslipidemia was defined as self-reported current treatment with cholesterol-lowering medication or having 1 or more of the following: Total cholesterol $\geq 5.2 \mathrm{mmol} / \mathrm{L}$,
Triglyceride $\geq 1.7 \mathrm{mmol} / \mathrm{L}, \mathrm{HDL}$ cholesterol $<1.0 \mathrm{mmol} / \mathrm{L}$ or LDL cholesterol $\geq 3.4 \mathrm{mmol} / \mathrm{L}$.

\section{Statistical Analysis}

Data analysis was performed using SPSS 20 statistical package. Descriptive analysis of numerical data was expressed as mean, standard deviation and range, test of Normality was conducted within the groups. Variation between the two study groups were analyzed using t test or Mann Whitney $U$ test depending upon the normality test. In case of categorical variables, they were expressed as frequency and percentage. Categorical data was analyzed using chi-square test. If the p value was $<0.05$ then it was considered statistically significant.

\section{Results}

Socio-demographic characteristics of the study population. There were total 130 participants, age of participants ranged from 20 to 81 years with mean age of 46.62 , among them $70(53.8 \%)$ were male. The participants were further divided in two groups on the basis of their age. Male participant aged less than 45 and female participants aged less than 55 were grouped as young age group which included total of $80(61.5 \%)$ participants and the remaining were grouped as old age group. Among the participants, three had previous history of Myocardial Infarction (MI) in past. Literacy and employment status of the participants were also recorded. Details are presented in Table 1.

Prevalence of various risk factors of CVD in study population The prevalence of CVD risk factors among the study population are summarized in table 2 . Among the risk factors, insufficient physical activity $(68.5 \%)$ was most prevalent within the study population followed by high waist circumference $(67.7 \%)$, obesity (59.2\%), hypertension (37.7\%), tobacco consumption (37.5\%), dyslipidemia $(22.3 \%)$, positive family history of coronary heart disease $(21.7 \%)$ and diabetes $(16.9 \%)$.

Among the gender wise analysis, tobacco consumption was significantly higher in male group $(64.3 \%$ vs $6.7 \%)$ whereas sedentary life style was significantly higher in female population $(57.1 \%$ vs. $81.6 \%)$. Other risk factors were similarly distributed among the two gender groups. All the prevalence of various risk factors among the participants and its gender wise variation are shown in table 2.

Further analyzing the prevalence of risk factors among the two study groups $\mathrm{A}$ and $\mathrm{B}$, Tobacco consumption rate was significantly higher in male respondents, in overall study population and in both age groups. Other risk factors were comparatively similar in both genders in both age groups as shown in Table 3.

\begin{tabular}{|l|l|l|l|}
\hline \multicolumn{1}{|c|}{ Table 1. Distribution of socioeconomic characteristic of respondents } \\
\hline \multicolumn{1}{|c|}{ Characteristics } & \multicolumn{1}{|c|}{ Categories } & \multicolumn{1}{c|}{ Number } & \\
\hline \multirow{3}{*}{ Mean age } & $\begin{array}{l}\text { Overall-46.62 } \\
\text { Male-47.06 } \\
\text { Female- 46.12 }\end{array}$ & $80($ Male-30, Female 50) & 61.5 \\
\hline \multirow{2}{*}{ Age group } & Young group & $50($ Male- 40, Female 10) & 38.5 \\
\hline \multirow{2}{*}{ Gender } & Old group & 70 & 53.8 \\
\hline & Male & 60 & 46.2 \\
\cline { 2 - 4 } & Female & & \\
\hline
\end{tabular}




\begin{tabular}{|c|c|c|c|}
\hline \multirow{4}{*}{ Religion } & Hindu & 70 & 53.8 \\
\hline & Christian & 26 & 20 \\
\hline & Buddhist & 33 & 25.4 \\
\hline & Muslims & 1 & 0.8 \\
\hline \multirow{8}{*}{ Education level } & Illiterate & 11 & 8.5 \\
\hline & Primary & 29 & 22.3 \\
\hline & lower Secondary & 17 & 13.1 \\
\hline & Secondary & 15 & 11.5 \\
\hline & SLC passed & 27 & 20.8 \\
\hline & Certificate level & 25 & 19.2 \\
\hline & Bachelor & 4 & 3.1 \\
\hline & Masters & 2 & 1.5 \\
\hline \multirow{3}{*}{ Marital status } & Single & 22 & 16.9 \\
\hline & Married & 100 & 76.9 \\
\hline & Widowed & 8 & 6.2 \\
\hline \multirow{5}{*}{ Employment status } & Unemployment & 20 & 15.4 \\
\hline & Employment & 60 & 46.2 \\
\hline & Retirement & 11 & 8.5 \\
\hline & Disabled & 2 & 1.5 \\
\hline & Others & 37 & 28.5 \\
\hline \multirow{6}{*}{ Occupation } & Agriculture & 19 & 14.6 \\
\hline & Animal Farming & 2 & 1.5 \\
\hline & Business & 34 & 26.2 \\
\hline & House Wife & 26 & 20.0 \\
\hline & Service & 10 & 7.7 \\
\hline & Others & 39 & 30.0 \\
\hline History of MI/Stroke & $\begin{array}{l}\text { MI } \\
\text { Stroke }\end{array}$ & $\begin{array}{l}3 \text { (Male-2, Female-1) } \\
0\end{array}$ & $\begin{array}{l}2.3 \\
0\end{array}$ \\
\hline
\end{tabular}

\begin{tabular}{|l|l|l|l|l|}
\hline \multicolumn{2}{|l|}{ Table 2. Prevalence of CVD risk factors among the study population } \\
\hline \multicolumn{1}{|c|}{ Male (\%) } & \multicolumn{1}{|c|}{ Female (\%) } & \multicolumn{1}{c|}{ Total (\%) } & \multicolumn{1}{c|}{ p value } \\
\hline Hypertension & $27(38.6)$ & $22(36.7)$ & $49(37.7)$ & 0.48 \\
\hline DM & $11(15.7)$ & $11(18.3)$ & $22(16.9)$ & 0.43 \\
\hline Tobacco consumption & $45(64.3)$ & $4(6.7)$ & $49(37.5)$ & $0.001^{*}$ \\
\hline Family history & $19(27.1)$ & $11(18.3)$ & $30(21.7)$ & 0.164 \\
\hline $\begin{array}{l}\text { Insufficient Physical } \\
\text { activity }\end{array}$ & $40(57.1)$ & $49) 81.6)$ & $89(68.5)$ & $0.002^{*}$ \\
\hline Dyslipidemia & $21(30)$ & $8(13.3)$ & $29(22.3)$ & $0.018^{*}$ \\
\hline Obesity & $36(51.4)$ & $41(68.3)$ & $77(59.2)$ & $0.004^{*}$ \\
\hline High WC & $38(54.3)$ & $50(83.3)$ & $88(67.7)$ & $0.001^{*}$ \\
\hline
\end{tabular}




\begin{tabular}{|l|l|l|l|l|l|l|l|l|l|}
\hline \multicolumn{2}{|c|}{ Table 3. Comparison of prevalence of CVD in different age group } \\
\hline & M & F & Total (\%) & p & M & F & Total(\%) & p \\
\hline N & 30 & 50 & 80 & & 40 & 10 & 50 & \\
\hline HTN & $6(20 \%)$ & $14(28 \%)$ & $20(25)$ & 0.3 & $21(52.5)$ & $8(80)$ & $29(58)$ & 0.11 \\
\hline DM & $1(3.3 \%)$ & $6(12 \%)$ & $7(8.7)$ & 0.18 & $10(25)$ & $5(50)$ & $15(30)$ & 0.125 \\
\hline Tobacco & $19(63.3)$ & $2(4)$ & $21(26.2)$ & $0.0001^{*}$ & $26(65)$ & $2(20)$ & $28(56)$ & $0.001^{*}$ \\
\hline Dyslipidemia & $8(26.7)$ & $6(12)$ & $14(17.5)$ & 0.08 & $13(32.5)$ & $2(20)$ & $15(30)$ & 0.36 \\
\hline $\begin{array}{l}\text { F a m i l y } \\
\text { History }\end{array}$ & $6(20)$ & $8(16)$ & $14(17.5)$ & 0.43 & $13(32.5)$ & $3(30)$ & $16(32)$ & 0.60 \\
\hline $\begin{array}{l}\text { S e d e n t a ry } \\
\text { life style }\end{array}$ & $19(63.3)$ & $41(82)$ & $50(62.5)$ & 0.06 & $21(52.5)$ & $8(80)$ & $39(78)$ & 0.11 \\
\hline \multicolumn{1}{|c|}{ Obesity } & $12(40)$ & $22(44)$ & $34(42.5)$ & 0.13 & $36(90)$ & $7(70)$ & $43(86)$ & 0.09 \\
\hline High WC & $10(33.3)$ & $42(84)$ & $52(65)$ & $0.007^{*}$ & $28(70)$ & $8(80)$ & $36(72)$ & 0.13 \\
\hline
\end{tabular}

\section{Discussion}

Our study assessed the prevalence of cardiovascular risk factors in one of the most urban area of the country. We found high prevalence of obesity indices, sedentary life style, hypertension, tobacco consumption, dyslipidemia and diabetes in our study group. The prevalence of almost all the studied cardiovascular risk factors increased with age.

Tobacco use is one of the most important modifiable risk factors for increasing cardiovascular disease. In our study, the prevalence of current tobacco consumption was $37.5 \%$ which was higher than the study done among Nepali medical students $22 \%$ and in Patna $12.5 \%$. Our study result was similar to the nationwide survey done in 2006 by Sreeramareddy et $\mathrm{al},{ }^{8}$ which showed the prevalence of tobacco consumption was $30.3 \%$. Smoking and tobacco consumption were significantly high in male population (64.3 vs 6.7) in overall as well as among all age groups in our study. This result was similar to some recent studies. ${ }^{910}$

Hypertension, a common health problem, is rising steadily in developing country. ${ }^{11}$ The study conducted in early 80 s by Pandey et $\mathrm{al}^{12}$ showed prevalence of hypertension was only $5.98 \%$ in rural population in Nepal, however recent studies conducted by Sharma et $\mathrm{al}^{10}$ in 2005 sub urban area of Kathmandu, revealed that prevalence of hypertension among people aged 50 years and above was around $42 \%$. Prevalence of Hypertension in our study was relatively higher as compared to previous studies, $37.7 \%$ in overall population, whereas in old age group it was as high as $58 \%$. This shows rapidly increasing trend of hypertension in Nepalese population. Various studies ${ }^{13,14}$ have shown that hypertension is more prevalent in men compared to women, whereas, some other studies ${ }^{15,16}$ showed female preponderance. Our study however revealed that Hypertension is slightly higher in male(38.6\% vs $36.7 \%)$, but were statistically insignificant, this result was similar to study conducted by Manandhar K et al. ${ }^{17}$

Diabetes mellitus is a chronic metabolic disease affecting almost all organ system in the body. Prevalence of Diabetes in our study was $16.9 \%$ which was slightly higher than that in Nationwide 2007 non communicable disease Risk Factor Survey $(10.8 \%)$ and in another study done by Sharma SK et a ${ }^{18}$ $(6.3 \%)$ in 2011 in eastern part of Nepal. Sex disparity in prevalence was not significant in our study as well as in nationwide national survey.
In Asian countries, the prevalence of overweight and obesity is increasing. Particularly, a moderate increase in body mass index, makes South Asians more prone to develop diabetes and cardiovascular diseases. Our study found about $60 \%$ of the study populations were obese according to their Body Mass Index (BMI) which also put them at risk of developing cardiovascular disease which is little higher as compared to a study done in Kavre, ${ }^{17}$ which showed $54.4 \%$. High WC was prevalent in $66.7 \%$ of total respondent which was higher than some other studies done in Nepal but different population groups. ${ }^{18}$ Higher prevalence of obesity and high WC have been more prevalent in women as compared to men in our study as well as some studies done in some developing countries, ${ }^{19,20}$ consistent with the sedentary lifestyle in women population.

There were some important facts that were prevalent in our study. Conventional risk factors are in rising trend in Nepal, especially in urban population as shown by increasing prevalence of hypertension, diabetes, and dyslipidemia in our study as compared to previous studies. Other very important factor highly prevalent in our study was smoking and tobacco consumption, which, despite several anti tobacco campaigns in national levels over the course of time, is still the same or even slightly higher. In most part of Nepal, there is belief that Heart disease is disease of male population, but significantly high prevalence of sedentary life style and obesity in female population in our study indicate that women are at equal or even high risk of developing cardiovascular disease as compared to men. Sedentary life style is increasing due to the lack of public awareness, very few public parks, and unplanned constructions and spending more time in environments that not only limit physical activity but requires prolonged sitting - at work, at home, in cars and communities.

Our study has some limitations as the sample size is relatively small and it is a single ward study.

\section{Conclusion}

Present study showed high prevalence of hypertension, tobacco use, insufficient physical activity, overweight and obesity among urban population of Kathmandu, suggesting possibility of higher incidence of cardiovascular disease in future, hence pointing towards the need of aggressive preventive strategy to prevent epidemic of cardiovascular disease. 


\section{Acknowledgements}

We would like to express our great appreciation to the department of Cardiac Rehabilitation of Shahid Gangalal National Heart Centre for helping organize and conduct this study. We would also like to convey special thanks to Mr. Surendra Lal Shrestha and staffs of Kathmandu Heart Foundation for their support and assistance throughout the data collection period.

\section{Reference}

1. John F. Beltrame, Rachel Dreyer and Rosanna Tavella (2012). Epidemiology of Coronary Artery Disease, Coronary Artery Disease - Current Concepts in Epidemiology, Pathophysiology, Diagnostics and Treatment, Dr. David Gaze (Ed.), ISBN: 978-953-51-0262-5.

2. Global status report on noncommunicable diseases. 2010. Available from: http://www.who.int/nmh/publications/ ncd_report_full_en.pdf

3. Fuster V, Rajesh Vedanthan, Bridget B. Kelly, et al . Promoting Global cardiovascular Health: Moving Forward. Circulation 2011; 123:1671-78.

4. Buttar HS, Li T, Ravi N. Prevention of cardiovascular diseases: Role of exercise, dietary interventions, obesity and smoking cessation. Experimental and clinical cardiology. 2005;10:229-49.

5. Misra A, Vikram NK, Gupta R et al. Waist circumference cutoff points and action levels for Asian Indians for identification of abdominal obesity. 2006; 30(1):106-111.

6. American Diabetes association. Classification and Diagnosis of Diabetes. Diabetes Care 2015; 38(1):S8-S16.

7. Expert Panel on Detection, Evaluation, and Treatment of High Blood Cholesterol in Adults E and T of HBC in A. Executive Summary of the Third Report of the National Cholesterol Education Program (NCEP) Expert Panel on Detection, Evaluation, and Treatment of High Blood Cholesterol in Adults (Adult Treatment Panel III). JAMA J Am Med Assoc. 2001;285(19):2486-2497.

8. Sreeramareddy CT, Ramakrishnareddy N, Harsha Kumar $\mathrm{H}$, et al. Prevalence, distribution and correlates of tobacco smoking and chewing in Nepal: a secondary data analysis of Nepal Demographic and Health Survey-2006. Subst Abuse Treat Prev Policy. 2011;6(1):33.
9. Walia R, Bhansali A, Ravikiran M, et al. High prevalence of cardiovascular risk factors in Asian Indians: a community survey - Chandigarh Urban Diabetes Study (CUDS). Indian J Med Res. 2014;139(2):252-9.

10. Sharma D, Bkc M, Rajbhandari S, et al. Study of Prevalence, Awareness, and control of Hypertension in a Suburban Area of Kathmandu, Nepal. Indian Heart J.2006; 58(1):34-7.

11. Hacihasanoglu R, Inandi T. Europe PMC Funders Group Frequency, Awareness, Treatment and Control of Hypertension in the over 40 Population of Erzincan. Turk Silahli Kuvvetleri Koruyucu Hekim Bul. 2014; 13(5): 357366.

12. Pandey MR, Upadhyaya LR, Dhungel S, et al. Prevalence of hypertension in a rural community in Nepal. Indian Heart J. 1980;33(6):284-9.

13. Stein AD, Stoyanovsky V, Mincheva V, et al. Prevalence, awareness, treatment and control of hypertension in a working Bulgarian population. Eur J Epidemiol. 2000;16(3):265-70.

14. Velázquez Monroy O, Rosas Peralta M, Lara Esqueda A, et al. Arterial hypertension in Mexico: results of the National Health Survey 2000. Arch Cardiol México. 2001;72(1):7184.

15. Jenei Z, Páll D, Katona E, et al. The epidemiology of hypertension and its associated risk factors in the city of Debrecen, Hungary. Public Health. 2002;116(3):138-44.

16. Tsai P-S, Ke T-L, Huang C-J, et al. Prevalence and determinants of prehypertension status in the Taiwanese general population. J Hypertens. 2005;23(7):1355-60.

17. Manandhar K, Koju R, Sinha NP, et al. Prevalence and associated risk factors of hypertension among people aged 50 years and more in Banepa Municipality, Nepal. Kathmandu Univ Med J. 2012;10(39):35-8.

18. Sharma SK, Ghimire A, Radhakrishnan J, et al. Prevalence of hypertension, obesity, diabetes, and metabolic syndrome in Nepal. Int J Hypertens. 2011;2011:821971.

19. Misra A, Khurana L. Obesity and the Metabolic Syndrome in Developing Countries. J Clin Endocrinol Metab, 2008;93(11):S9 -S30.

20. Tappy L, Bovet P, Shamlaye C. Prevalence of Diabetes and Obesity in the Adult Population of the Seychelles. Diabet Med. 1991;8(5):448-452.
Cite this article as: Amrit Bogati, Reeju Manandhar, Deewakar Sharma, et al. Prevalence of Cardiovascular risk factors among the residents of urban community of Kathmandu municipality. Nepalese Heart Journal 2017; 14(1):3-7. 